\title{
Plain English in Legal Language: A Comparative Study of Two UK Acts of Parliament
}

\author{
Catalina Riera \\ University of Alicante \\ catalina_maria15@hotmail.com
}

\begin{abstract}
The history of England has left its mark on legal English, a language for specific purposes well known for its complexity and conservatism throughout the world, thanks to the widespread reach of the British Empire. According to many scholars, today legal language is excessively entrenched in the past and has remained the same through years. As a consequence, criticism against traditional legal drafting started to arise in the second half of the 20th century introduced by the Plain English Movement, first in the UK and then, with more momentum, in the US. Its supporters fight for the simplification of the language used in legal documents - and subsequently, all official documents- and propose a series of writing techniques to achieve their purpose of making "legalese" more accessible to the lay public.

The aim of this paper is to see whether the drafting of Acts of Parliament in the United Kingdom (UK) has evolved towards a more modern style of writing leaving behind the conservatism that characterises legal language. In order to carry out the study, two Acts of Parliament of the UK on the same topic, but with a time span of 41 years of difference since their enactment, have been selected for comparison in order to see whether the principles upheld by the Plain English defenders have been applied in the most recent Act.
\end{abstract}

Keywords: legal English; language for specific purposes; language for legal purposes; Plain English Movement; UK Acts of Parliament 


\section{Introduction: the Plain English Movement}

Legal documents are characterised by a conservative, complex and fossilized style of language, characteristically termed "legalese". Some of the changes in today's legal language can be attributed to a number of complaints by the Plain English Movement, which works towards achieving a plainer style of legal drafting so as to make legal documents more accessible to the lay public. Their aim is to encourage legal professionals to write clearly, avoiding awkward and complex language, and taking into consideration the lay reader. Bearing this in mind and in order to modernise and simplify the language of the law, they propose a series of linguistic principles to be followed in the drafting of legal documents.

Though several reformers, such as Jeremy Bentham or George Coode, had criticised traditional legal language during the 19th century, it was not until the second half of the 20th century that more generalised protests began to be heard, especially in the USA. In the 1970s, the consumer movements, in order to protect consumers' rights, started a number of protests and, as Adler (2012: 69) reminds us, "various initiatives, encouraged by the belief that citizens should be able to understand their rights and obligations, had built up sufficient momentum to be identified as the beginning of the current movement". One initiative that was considered the initial landmark of the movement in the legal sphere is associated with Citibank in New York which, in 1973, released a promissory note drafted in plain language whose success influenced the writing of insurance and banking fields (Williams, 2007: 168). From then on, the movement started to spread to other English-speaking countries such as Canada, Australia, New Zealand and the United Kingdom.

In 1978, the government of the United States joined the movement when President Carter signed Executive Order 12044, which imposed that the regulations issued by the Executive Agencies should be "as simple and clear as possible" and added that the head of each agency should determine that "the regulation is written in Plain English and is understandable to those who must comply with it". ${ }^{1}$ In November of the same year, the State of New York enacted the so-called "Sullivan law", the first general Plain English statute in America which required the use of clear and common words in drafting of residential leases and consumer contracts. This statute influenced other states, which passed a number of regulations that required the use of Plain English in insurance policies and consumer documents (Butt \& Castle, 2006: 101).

One year later, in 1979, the United Kingdom, saw the birth of the most influential organisation around the world, the Plain English Campaign, launched by Chrissie Maher and Martin Cutts to fight "gobbledygook and jargon". The organisation's aims in the legal sphere are not only to replace jargon by common words, but also to consider the content and the layout of the text. They also provide services for rewriting documents and courses to train people on the basis of Plain English. In their first booklet, entitled Writing Plain English, they provided a number of recommendations such as sticking to the essential information, using everyday words, selecting a clear layout and typeface, and building sentences with no more than two clauses (Butt \& Castle, 2006: 81). 
Given the status of English as a global language, organisations working to promote the aims of the Plain English Movement are now active all over the world and also exist for other languages. They spread and defend its principles, and to achieve their purpose, provide language services to revise documents and ensure they follow a plain drafting style. Many of them also offer high-quality writing-skill courses to companies and organisations. In the United Kingdom, for example, apart from the Plain English Campaign, there are other organisations which support the application of Plain English such as Clarity (http://www.clarity-international.net/) and the Plain Language Commission (http://www.clearest.co.uk/). Regarding the United States, the principles of the movement have been supported by many Bar Associations that promote the use of a clear and simple language among lawyers such as the State Bar of Michigan, which includes a monthly Plain Language column in the Michigan Bar Journal (http://www.michbar.org/journal/home). One of the most important developments in the US took place when President Barack Obama signed the 'Plain Writing Act of 2010', a federal law that provides for the use of plain writing by federal agencies. Canada is one of the leading champions of the movement, and, as confirmed by Williams (2007: 175), "the Canadian Securities Administration, the federal Department of Finance, the British Columbia Securities Commission, the Office of the Alberta Auditor General, and the Canadian Banker's Association are all in favour of using Plain English". Moreover, the country is the birthplace of the Plain Language Association International (http://plainlanguagenetwork.org/), a non-profit organisation of plain language advocates and consultants whose aim is to promote clear communication. In Australia, the most prominent figure of the Plain English Movement is Robert Eagleson, who fought for the rewriting of statutes in Plain English. The organisation in charge of promoting plain language is the Plain English Foundation (https://www.plainenglishfoundation.com/). Such is the power of the movement in Australia that "companies can face legal sanction should they be found to have intentionally misled consumers with contracts that contain confusing, unintelligible language" (Barleben, 2003).

Not content with simply protesting against legalese, Plain English advocates have also proposed a series of concrete linguistic techniques to apply to legal texts in order to avoid complexity and obscurity and enhance clarity and comprehension. The following writing guidelines have been taken from the works of Plain English defenders such as Kimble (1992), Plain English Campaign (1996), Butt \& Castle (2006), Williams (2007) and Adler (2012). The principles have been divided into two different categories: on the one hand, those related to language and grammar and, on the other, all the techniques related to the design and structure of the document:

- $\quad$ Language and grammar level:

- Substitute nominalisation by the use of verbs since they make the message clearer and more direct.

- Use the active voice instead of the passive when possible.

- Be concise and avoid using complex and wordy phrases. 
- Substitute archaisms, and foreign words (Latin and French) by familiar words which tend to be shorter.

- Avoid doublets (null and void) and triplets (give, devise and bequeath).

- Avoid overusing shall and replace it by must or the present simple, or in some cases by may.

- Keep the Subject - Verb - Object structure and avoid intrusive phrases.

- Avoid the abundance of negatives.

- Write according to the grammar rules.

- Design and structure:

- Reduce the sentence length to an average between 15 and 20 words.

- Keep paragraphs short using sub-paragraphs in order to avoid long blocks of text.

- Use lists or fragment sentences.

- Use blank spaces in margins and between sections.

- Avoid overusing initial capital letters, which are used in legal documents in terms that have been previously defined. It is better to use them only when the language norm requires it.

- Use tables, graphs, diagrams and charts to make explanations clearer.

- Use italics or bold letters for the heading or as emphasizing techniques.

\section{Views on the application of Plain English in the language of the law}

Not all advocate in favour of Plain English, and indeed the Plain English Movement has its detractors. One such example is Rabeea Assy who, in his article "Can the Law Speak to its Subjects? The Limitation of Plain English" (2011), criticises the Plain English Movement, which he considers has spread the false belief that law can speak directly to its subjects by simplifying its language. He adds that although the law may be written in plain language, it cannot be made sufficiently intelligible as to enable lay people to use it without legal assistance due to the fact that the content of the law is generally too complex for people without legal training to understand. Nevertheless, Assy proposes two different uses of the plain language. On the one hand, he states that plain language can be used to clarify the law for lawyers in order to improve the quality and efficiency of their legal services. On the other, he argues that plain language enhances the capacity of lay people to evaluate the service provided by the lawyers and the legal service.

Brian Hunt, though generally considered a defender of Plain English, nevertheless does agree in some of his publications (Hunt, 2002a, 2002b) that the aim of legislation is not to entertain but to make policies and principles in law effective, which explains that certain terms are used in legal texts for their precision and consistency of meaning. For him, using Plain English to draft complex concepts such as legislation would not be appropriate since it can increase ambiguity and vagueness, giving rise to different interpretations. For this reason, Hunt believes that the best solution is to accompany 
each piece of legislation by explanatory material in plain language for the benefit of the lay public.

Regarding the views in favour of the implementation of Plain English, the Plain English Campaign (1996: 16), which tackles the issue of comprehension from a moral point of view, offers the most interesting position, saying that "the ability to understand the law is a basic right and a basic need. [...] if people cannot understand the legal documents which they must live by, you have to ask quite what we mean by a 'democratic society"'.

Kimble (1994-95: 52), another defender of the modernisation of legal language, declares that the only purpose of plain language is to convey clear and effective communication. The same author (1303) further argues that Plain English does more for precision than legalese, and its "principles can usually make even complicated ideas more clear. Or if not more clear, at least as clear as can be." In another of his articles (Kimble, 1996-1997: 2), he points out that many projects have proved that complex concepts can be put into Plain English without losing accuracy or precision and adds that "plain language is not just about vocabulary. It involves all the techniques for clear communication - planning the document, designing it, organizing it, writing clear sentences using plain words, and testing the documents whenever possible on typical readers".

When a new movement arises questioning the effectiveness of what has existed for centuries, it is understandable that different opinions emerge. After this brief overview of the Plain Language Movement and the issues it raises, we now propose to carry out an empirical study of the degree to which plain language has been incorporated -or notinto official legal English in Britain by analysing two Acts of Parliament which present a 41-year difference in their dates of enactment. The analysis is carried out to check whether, as one would expect, the most recent Act has followed the Plain English drafting style, and that the ideas that the movement supports have been applied to any significant extent.

\section{Our study: methodology}

The first step consisted of finding two Acts of Parliament of the United Kingdom pertaining to the same legal area, the requirement being that one had to be enacted before the Plain English Movement had started developing in the UK in the late 1970s, while the other had to be as recent as possible. After a review of the official website of the British government, www.legislation.gov.uk, which contains all UK legislation from the year 1801 until 2015, it was decided that the Act that best suited the search criteria was the Water Act, one version of which dated back to 1973. This was considered an acceptable date because, although by then criticism against the complexity of legal documents had already begun to be heard, it was not until the end of the 1970s that the movement started to gain some degree of relevance in the United Kingdom. For the second element required for the comparative study, Water Act passed 
in 2014, a time when the movement was already very active and influential, seemed appropriate to the analysis criteria.

The object of our analysis being to determine whether Plain English principles are applied in contemporary UK legal drafting or not, the choice of the criteria used for the analysis has been based on the linguistic principles upheld by the Plain English Movement. Some of the linguistic aspects of traditional legal drafting, mentioned in the first section, have been studied in the two Acts; hence we shall comment on the design and structure, modal auxiliaries, the prepositional adverbs, passive sentences, Subject Verb - Object structure, complex prepositional phrases, and nominalisation. In each part, we shall comment on what the traditional tendency is and what the Plain English defenders say on each matter, to judge whether the Act of 2014 follows the traditional style or has evolved towards Plain English.

\section{Our analysis}

\subsection{Design and structure}

The design of legal texts is attached to the principles of precision and avoidance of ambiguity, which explains why these texts contain extremely long sentences, with several qualificational insertions required, and solid blocks of text that end up making the document complex and difficult to understand.

Regarding textual schematisation, both Acts show a schematized structure, that is, the contents of the text are arranged in a schematic way using lists, sections and subsections; however, in the 1973 Act there are a number of long textual blocks that make it difficult to understand. Sentence length is another element to be taken into consideration in this context. In the 1973 Act the shortest sentence has 8 words and the longest one 283. Most of the sentences are of considerable length, but the subject of some of them is separated into different sections, which makes the sentence slightly more accessible. Nevertheless, despite the fact that schematisation is a technique used to make long sentences clearer, the 1973 Act also shows an abundance of long textual blocks -the longest being composed of 154 words- that hinder access to the real message. Additionally, the flow of information in the sentence is disrupted by the insertion of several elements that are included to provide further information on a given element.

In the 2014 Act, we can observe that schematisation is more developed. In the old Act there is a combination of solid blocks of texts and of schematised sentences, whereas in the 2014 Act there are no long textual blocks since the division of the sentence into alphabetically itemized lists, sections and sub-sections prevails, mainly in sentences of considerable length, even though shorter ones also follow this layout.

According to Plain English supporters, 15-20 words is the appropriate sentence length to enhance comprehension. In the 2014 Act, though there are only a few sentences whose length agrees with the sentence length required by the Plain English 
principles, one can observe a positive evolution regarding the number of solid blocks in the 1973 Act.

\subsection{Modal auxiliaries}

One of the most specific characteristics of traditional legal drafting in English is the use of the modal auxiliary shall. The problem with this auxiliary is the many purposes it has come to serve and the several meanings that have been attributed to it. Some of these meanings are imposing a duty, granting a right, giving a direction, expressing future, negating a duty, stating circumstance, expressing an intention, creating a subsequent or precedent condition, or negating a right (Butt \& Castle, 2006: 131). As a result, it causes ambiguity, and precision is lost.

The Plain English Movement opposes the overuse of shall, not only because of its ambiguity, but also because in general English its use as an auxiliary of the future tense has declined, not to mention its absence as a deontic. Modern drafters support the total removal of shall from legal writing in favour of its replacement by the everyday auxiliaries of obligation, must and be to.

In the 1973 Act shall accounts for $1.5 \%$ of the total number of words. The majority of the cases impose an obligation or a duty, and others impose a prohibition using shall not, such as in the following examples, taken from the 1973 Act:

Each of the authorities mentioned in subsection (1) above shall be established by an order made by the Ministers and shall come into existence on a day appointed by the order.

Provided that, in the case of an order to which paragraph 16(2) above applies, the notice shall not be published until the expiry of the period of twenty-eight days referred to in that sub-paragraph.

An analysis of the use of shall in the Water Act of 2014 shows completely different results since we only find 5 occurrences, which represents $0.005 \%$ of the total number of words. The use of shall, it may consequently be concluded, has plummeted over the forty-one year period separating the two texts. However, if shall has been largely removed from the 2014 Act, other alternatives have been introduced in order to fulfil the functions performed by shall. As previously indicated, Plain English drafters support the use of must and be to for purposes of expressing obligation. In view of this, the use of must has been analysed. In Table 1 below, we find the results obtained in the analysis: 
Table 1. Evolution of use of alternative modals to shall between 1973 and 2014

\begin{tabular}{lcc}
\hline & $\begin{array}{c}1973 \text { Act } \\
\text { Total no. of words: } \\
48,544\end{array}$ & $\begin{array}{c}\text { Total no. of words: } \\
95,542\end{array}$ \\
\hline must & $0.004 \%$ & $0.34 \%$ \\
are to be & $0.018 \%$ & $0.066 \%$ \\
is to be & $0.043 \%$ & $0.15 \%$ \\
\hline
\end{tabular}

It can be deduced from these data that the 41-year period separating these two texts has seen a clear evolution from shall to must and be to, in keeping with Plain English recommendations.

Another modal auxiliary that must be mentioned is may, the second most used modal auxiliary in legal texts (Williams, 2007: 121), whose meaning in the affirmative form is that of conferring a power, whereas in the negative form it imposes prohibition. On some occasions, may can also express possibility. It is worth noticing how the use of may has changed through the years. In the 1973 Act, the frequency of may is a mere $0.7 \%$ of the total number of words, while in the 2014 Act it increases to $1.04 \%$. As Williams (2007: 121) suggests, shall not is more common than may not when a prohibition is to be expressed, but he adds that in the texts in which Plain English recommendations have been applied, may not is more frequent. The two Acts have been analysed with regard to these remarks, and it has been observed that while, in the 1973 Act shall not has a percentage of $0.12 \%$ and may not only $0.006 \%$, in the 2014 Act, the situation is reversed, and may not has a frequency of $0.10 \%$, whereas that of shall not is $0.001 \%$, appearing once in the whole text.

Figure 1 below illustrates the data from the comparison. As can be appreciated, shall and shall not predominate in the 1973 Act, which is drafted in traditional legal style; in the 2014 Act, on the contrary, the use of shall and shall not is barely noticeable. Must, which in modern drafting is used to replace shall, has a significant presence in the recent Act, whereas in the old one its use is extremely low. The modal auxiliary that has not completely disappeared but has acquired a larger representation in the modern Act is may, both in the affirmative and the negative. Regarding the use of auxiliaries, it can be stated that the drafters of the 2014 Act do seem to have followed the principles upheld by the Plain English Movement. 


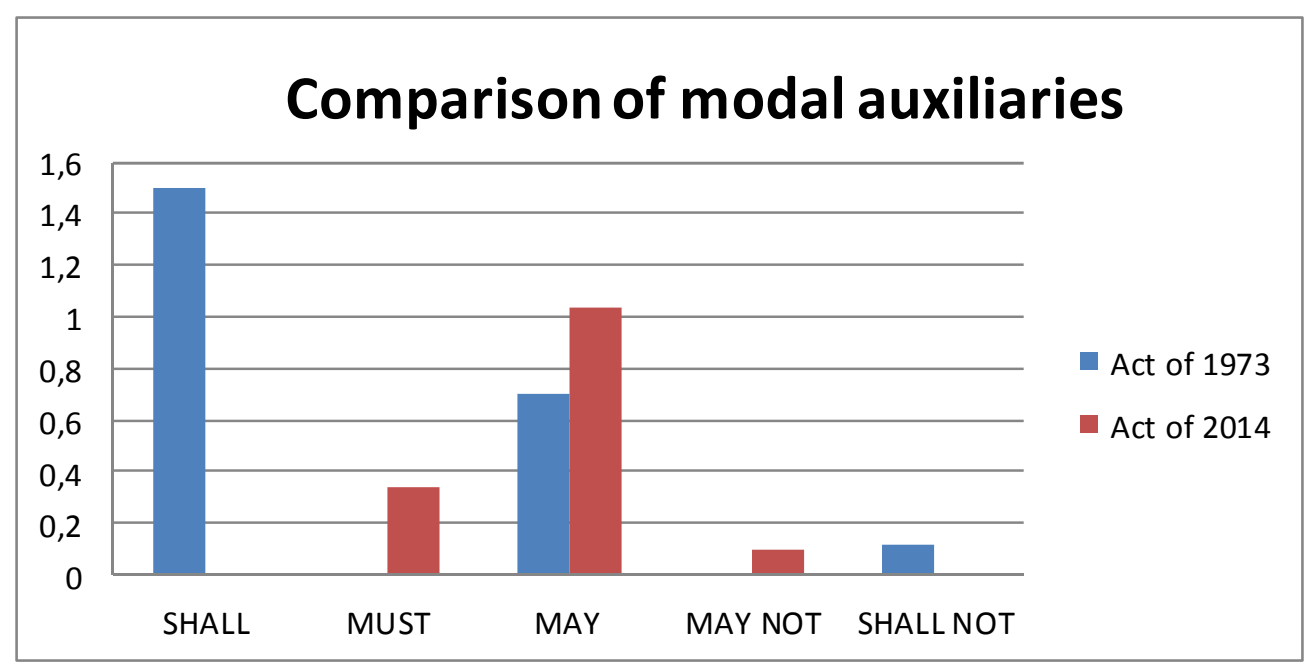

Figure 1. Comparison of the traditional modal auxiliaries in legal drafting in the two Acts.

\subsection{Prepositional adverbs}

The use of archaic words is another trait of legalese. Lawyers and drafters have a tendency for conservatism, and as a consequence they continue using the same terminology as their predecessors. More significantly perhaps, another justification for the presence of archaic words is the fact that they are thought to give more formality to the document than words from everyday language. The most emblematic archaic lexical items of legalese are prepositional adverbs or "semi-archaic formulations" (Haigh, 2015:7), such as heretofore, thereof, hereby, etc., which are still used in contracts and other legal documents.

As may be expected, the analysis shows that the 1973 Act shows a higher frequency of prepositional adverbial expressions, while in the 2014 Act, such use is consistently low or negligible: the 1973 Act contains cases of thereof, therefor, therein, therewith, thereon, thereunder, thereupon, thereby, thereafter, and hereby; as shown in the examples below:

The enactments specified in Schedule 9 to this Act (which include enactments that were obsolete or unnecessary before the passing of this Act) are hereby repealed to the extent mentioned in column 3 of that Schedule.

A person who wilfully obstructs another person exercising any power conferred by this section or any warrant thereunder shall be liable on summary conviction to a fine not exceeding $£ 50$.

In sharp contrast but unsurprisingly, the analysis reveals that in the 2014 Act there is not a single case of prepositional adverbs.

The use of prepositional adverbial expressions has been criticised because they are "foreign" to lay readers, and in this way, constitute an obstacle to comprehension and 
may lead to misinterpretation in that the relevant preposition has to be identified each time. For example, in the previous examples "any warrant thereunder" refers to any warrant "under the present section", and "hereby repealed" signifies that the enactments are repealed "by the present act". Though these expressions are generally only decipherable within the context in which they occur, on some occasions there are several elements that can act as antecedents, therefore adding to the confusion.

Regarding the use of other archaisms, Tiersma (1999: 89) mentions aforesaid and said as symbols of traditional legal drafting. They are used to refer to something or someone that has already been mentioned previously in the text, such as in these examples taken from the 1973 Act: "the said section" or "the said Schedule 3". With regard to our study, we observe that the two terms are only present in the 1973 Act, in which we find 31 cases of said $(0.06 \%)$ and 5 of aforesaid $(0.010 \%)$, whereas they are nowhere to be found in the 2014 Act.

Another archaic trait criticised by Tiersma (1999: 91) is the use of such in legal documents and which, according to him, performs the same function of this, and is undistinguishable from said and aforesaid. In context of this study, the percentage of such is $0.70 \%$ in the 1973 Act and though also present in the 2014 Act, it represents a frequency of only $0.47 \%$ of the total number of words. Such is said to be used wrongly by lawyers since in general language it means "of the character, quality, or extent previously indicated or implied" (Merriam Webster Dictionary Online). According to Garner's A Dictionary of Modern Legal Usage (1995) such in the legal context can also behave as a deictic to refer to a clear antecedent. Nevertheless, we also find examples with such used without a precedent, and also used when this, that or the would be more suitable. In the 2014 Act, most of the cases with such do not have a precedent to which they refer. On the contrary, in the 1973 Act, the use of such as a reference to a precedent prevails, even though there are also cases of such without a precedent. In the following example, we have a fragment from the 2014 Act in which we find two cases of such without a precedent:

by order require the supplier to give and the qualifying person to take a supply of water in bulk for such period and on such terms and conditions as may be specified in the order.

To conclude on this point, the above analysis clearly shows that archaisms in modern legal drafting have largely disappeared, mainly in the cases of prepositional adverbial expressions from Middle English, the same applies to said and aforesaid, whose presence has become null in the recent Act. The only traditional trait that persists is such, which still preserves some of the erroneous uses attributed to legal drafters, instead of other clearer and everyday used in everyday language such as this, the and that.

\subsection{Passive sentences}

Frequent use of the passive tense is another characteristic of legal language (Mattila, 2006: 73). Though the use of the passive form is often criticised as being used to avoid 
attributing responsibility, in the case of these texts it is mainly used for reasons of impersonality since in some cases the author of the action is not stated because it is not relevant. Plain English defenders criticise the overuse of the passive in legal texts, and state that the active voice is more appropriate because it shortens the sentence and is more direct.

In order to study the use of passives in the two Acts, a fragment of a considerable length from each Act with the same number of words was selected. In this case, the part of the text analysed consisted of 23,580 words, which account for $48 \%$ over the total number of words of the 1973 Act, and $24.6 \%$ of the 2014 Act (although the 2014 Act is twice as long as the 1973 one). A thorough manual analysis was carried out to detect the passives that were used in each Act. Once all the examples were identified, the number of cases was counted. The results obtained show that for the same number of words, there is a $0.89 \%$ of passive constructions in the 1973 Act, in comparison to $0.83 \%$ of passive constructions in the 1971 Act. The results, therefore, show that though we expected to find an extreme difference in the number of cases in the two Acts, the difference is not all that marked. In the 2014 Act, we find some cases of passives followed with a by-phrase identifying the agent of the action, such as in the example below, in which the agent could be moved to the front and act as the subject of the sentence. Thus, the sentences in which the agent is already mentioned could be arranged in the active voice as the Plain English advocates uphold. The presence of the agent in many of the sentences of the 2014 Act indicates that the passive voice is a grammar resource that still persists in the drafting of Parliamentary Acts, presumably because of the formality this structure provides to the text, and not to mask the doer of the action:

The power under subsection (4) may not be exercised more than once by the Secretary of State or the Welsh Ministers.

We note, though, that the types of passives used in each Act are slightly different. In the 1973 Act, the passives with shall prevail, together with the present simple passive and the present perfect passive, whereas in the 2014 Act, the construction is/are to be + participle acquires considerable relevance, together with passives with may and must, leading us to conclude that the change towards a more modern style is not reflected in the reduction of passives but through the way this grammar construction is used.

\subsection{Subject - Verb - Object structure}

English is a language that follows the Subject - Verb - Object (SVO) sentence structure. However, legislative syntax does not usually follow this order, since it demands the introduction of several qualifications that are inserted into the syntax of the sentence. The most common discontinuity these insertions involve may be seen in the separation of the parts of the verb. Plain English advocates are against syntactic interruptions and state that the SVO structure must be kept whenever possible.

As already mentioned, the 1973 Act presents solid blocks of text due to the several qualificational insertions that are embedded in the text, and thus the SVO structure is 
frequently interrupted. In this Act, there are several separations of the parts of the verb as in the following example, in which the words in italics highlight the syntactic intrusions, and the rest is the skeleton of the sentence:

If, within a period of two months beginning with the date on which a draft of any such arrangements was sent by a water authority to the company, the water authority and the company have not entered into the arrangements, the water authority shall, within seven days of the end of that period, notify the Secretary of State of that fact and the Secretary of State shall settle the terms of the arrangements, which shall, subject to subsection (5) below, be binding on the authority and the company.

In the 2014 Act there is a prevalence of short sentences instead of the solid blocks of text in the 1973 Act; in these cases the SVO structure is followed in the majority of them, even in sentences that have been broken into different sections. Nevertheless, there are still some sentences with intrusions, such as in the example below, in which the qualifications have been separated from the main text making use of the schematisation technique. In this instance, the Authority is being given instructions that can only be fulfilled if the cases stated in the qualificational intrusions take place:

On the application of the qualifying person or the established undertaker, the Authority may-

(a) if it appears to the Authority that it is necessary or expedient for the purposes of this Part that the established undertaker should permit a main connection into its sewerage system, and

(b) if the Authority is satisfied that the established undertaker and qualifying person cannot reach agreement,

by order require the established undertaker to permit the connection for such period and on such terms and conditions as may be specified in the order.

Bhatia (1994: 147) defends the insertion of qualifications in legislative provisions arguing that: "qualifications make the provision extremely restricted. In fact, without these qualifications the legislative provision will be taken to be of universal application and it is very rare that a rule of law is of universal application." This restricted application could, therefore, be the reason why qualificational intrusions, and the syntactic discontinuity they imply, are still present in today's legislative texts. However, it is worth noticing that in the 2014 Act, the long intrusions that can hinder the comprehension of the sentence have been drafted using the schematized technique so as to make it more accessible.

\subsection{Complex prepositional phrases}

Prepositional phrases are another aspect of legal English criticized by the Plain English defenders. These consist of complex phrases whose structure follows a preposition + noun + preposition pattern which is indeclinable, such as "in accordance with" or "on behalf of", which could be replaced by a single preposition, for example "under" for the 
former phrase and "for" for the latter. Plain English advocates claim that if the idea can be expressed in only one word, there is surely no need to use three or more since they slow up the comprehension and irritate the reader (Plain English Campaign, 1996: 76).

These phrases have been analysed in the Acts under study, and classified below together with their frequency. In this case, the significance of the frequencies must be considered in correlation to the number of words of each text.

\begin{tabular}{|c|c|c|c|c|c|}
\hline \multicolumn{3}{|c|}{1973 Act } & \multicolumn{3}{|c|}{2014 Act } \\
\hline $\begin{array}{c}\text { Prepositional } \\
\text { phrase }\end{array}$ & $\begin{array}{c}\text { No. of } \\
\text { cases } \\
(48,544 \\
\text { words })\end{array}$ & Percentage & $\begin{array}{c}\text { Prepositional } \\
\text { phrase }\end{array}$ & $\begin{array}{c}\text { No. of cases } \\
(95,542 \\
\text { words })\end{array}$ & Percentage \\
\hline by virtue of & 54 & $0.11 \%$ & by virtue of & 85 & $0.08 \%$ \\
\hline for the purpose of & 22 & $0.045 \%$ & $\begin{array}{l}\text { for the purpose } \\
\text { of }\end{array}$ & 62 & $0.064 \%$ \\
\hline in respect of & 36 & $0.074 \%$ & in respect of & 145 & $0.151 \%$ \\
\hline in pursuance of & 34 & $0.070 \%$ & in pursuance of & 23 & $0.024 \%$ \\
\hline with respect to & 34 & $0.070 \%$ & with respect to & 38 & $0.038 \%$ \\
\hline $\begin{array}{l}\text { in accordance } \\
\text { with }\end{array}$ & 41 & $0.084 \%$ & $\begin{array}{l}\text { in accordance } \\
\text { with }\end{array}$ & 178 & $0.186 \%$ \\
\hline in the event of & 1 & $0.002 \%$ & & & \\
\hline by reason of & 6 & $0.012 \%$ & & & \\
\hline
\end{tabular}

Table 2. Complex prepositional phrases detected in each Act and their frequencies

Table 1 shows the number of occurrences of the complex prepositional phrases in the two Acts, together with the percentage regarding the total number of words. Although it might seem that in some cases there is a higher presence in the 2014 Act, it is important to focus on the percentage column, since it allows us to establish a more faithful comparison. The two Acts share six complex prepositional phrases, amongst which "in pursuance of" $(0.70 \%)$, "with respect to" $(0.70 \%)$ and "by virtue of" $(0.11 \%)$ have a higher presence in the 1973 Act, whereas the use of "in accordance with" $(0.186 \%)$, "for the purpose of" $(0.064 \%)$ and "in respect of" $(0.151 \%)$ increases in the 2014 Act. These results show that there are no extreme differences between the two Acts and that complex phrases are still present in legal drafting.

Nevertheless, it should be pointed out that in the 2014 Act there are a number of cases of simple prepositions that perform exactly the same role as complex phrases, leading to the conclusion that, in this Act, complex phrases coexist with simple prepositions that could have replaced them. For example, "in accordance with" and "in pursuance of" can be replaced by the preposition "under". In this Act, we find 1257 cases $(1.31 \%)$ of 'under' that perform the same function as these complex phrases, whereas in the 1973 Act the use of 'under' is much lower with 363 cases which represents $0,74 \%$ of the total number of words. 


\subsection{Nominalisation}

Nominalisation, together with the passive voice, is a technique that favours not only impersonality but also wordiness due to the fact that the number of words in the sentence tends to increase. The example below is taken from Haigh (2015: 74) to demonstrate the effectiveness of changing nominalisations into verbs:

It is important to effect a reduction of operating costs during the implementation of the agreement.

It is important to reduce operating costs when implementing the agreement.

Garner (1995: 123), who calls nominalisation 'buried verbs', is against its use in legal drafting and argues that it is better to resort to action verbs instead, which will humanize the text since the agent of the action will be stated. Moreover, the text becomes less abstract and therefore it is easier for the reader to understand the intention of the drafter.

The majority of nominalisations found coincide in the two Acts. Nevertheless, the layout of the 2014 Act favours the use of action verbs, which explains why there are both the nominalised expressions and its equivalent action verb in the text. Some of the nominalisations most used in this Act are "make provision" $(0.14 \%)$ for 'provide'; "have regard" $(0.046 \%)$ instead of 'regard'; "give notice" $(0.047 \%)$ for 'notify'; and "subject to annulment" $(0.016 \%)$ instead of 'be annulled'; these 'buried verbs' appear recurrently throughout the text. Although the verb from which they derive is also present in the Act, the nominalised form has a higher frequency than the verbal one. Below, there are some examples of the nominalisation used in the 2014 Act:

Before issuing the revised rules, the Authority must give notice to the Minister of its intention to issue revised rules.

A statutory instrument containing an order made by the Welsh Ministers under this section is subject to annulment in pursuance of a resolution of the Assembly.

As can be observed in the examples above, they can be replaced by an action verb; thus, if in the previous cases "give notice" were replaced by 'notify', then the sentence would gain in economy of words and presumably, clarity. The same happens with "subject to annulment", which could be simplified to 'be annulled'. As these examples show, more words are included in the sentence when fewer would convey the message in the same way or even better since, the use of the verbal form makes the sentence more direct. Nominalisation is a technique of traditional legal drafting that still preserves a place in modern drafting, mainly because of the formality it provides to the text. 


\section{Discussion of results}

The purpose of this study was to measure the evolution from traditional legalese to Plain English through the analysis of two British Acts separated by a 41-year span. In the light of the results of the analysis, it may be said that while a number of the principles advocated by the Plain English Movement have been followed in the 2014 Act, other elements continue to adhere to the principles of traditional legal drafting.

Regarding the structure, it may be seen that there has been a change towards a more accessible layout since the techniques proposed by the Plain English Movement, such as alphabetically itemised lists and sub-paragraphs which avoid the ungraspable solid blocks of texts so typical of legal drafting.

In terms of modal auxiliaries, legislative texts have left behind the overuse of shall, which sometimes was ambiguous due to the several meanings that it could serve. As a consequence, there is a distinct shift towards must and be to when expressing obligation. In addition, the use of may has increased, namely in the negative, where shall not was previously used. As such, it can be said that modal auxiliaries are the most modernised aspect of legal drafting.

Another aspect that has undergone significant change is the use of archaisms. The archaic traits that strongly characterise legalese, such as the prepositional adverbs with there and here, said and aforesaid, are almost absent in the 2014 Act. Nevertheless, such resists the change and is employed when other alternatives like the, this or that would have been more suitable.

The passive voice is another characteristic of legal drafting most criticised by Plain English supporters. The comparative analysis carried out shows that the passive voice continues to have a significant use in modern legal drafting. However, we note that many of the passives have a by-phrase indicating the agent, and thus it is inferred that its persistence is more related to the formality this structure gives to the text rather than the impersonality it may involve.

The analysis of the Subject - Verb - Object structure shows that in the 2014 Act this order is followed in the majority of short sentences, but in some of the long ones the order is broken by qualificational intrusions that are inserted among these three key elements of the sentence. Nonetheless, it may be observed that the use of schematisation has favoured comprehension since in the majority of cases the intrusions have been separated from the main body of the sentence, leaving the sentence's main skeleton more visible.

Complex prepositional phrases have not disappeared totally from modern legal drafting. Many of them are so deeply rooted in traditional legal style that it will certainly take time to dispense with them.

Finally, regarding nominalisation, our analysis shows that it has not disappeared completely from legal drafting. In spite of the fact that it favours impersonality and verbosity, the formality it evokes gives this lexical trait a firm hold in legislation drafting. Nonetheless, it has been observed that the action verbs from which these nominalised expressions derive are also present in the Act. Therefore, although the 
frequencies are higher in the nominalised form, the verbal form has begun to acquire a certain presence.

In this sense, the hypothesis posed earlier is partially proved because we cannot see a total incorporation of plain language in all the aspects analysed. The only areas in which a considerable change may be detected are in the avoidance of archaic expressions, the layout and structure of the text, and the shift of modal auxiliaries. Concerning the rest, although elements of traditional legal style persist, in some of them it is possible to see some degree of evolution towards a more modern style such as in complex phrases, nominalisation and in the SVO structure. The element that still resists change is the passive voice whose persistency, as already highlighted, is bound to the formality the text demands and that this structure provides.

\section{Conclusion}

The language of the law has been entrenched in tradition and maintains a rather archaic and conservative style. Although the Plain English Movement has had a significant impact on the language of legal drafting, legislation is a genre which resists change and which cannot be completely replaced by a modern style in less than half a century.

The results appear to show that the process of adoption of a plain and modern style in these types of legislative text is slow. This slowness is due to the nature and functions of this particular textual genre, which requires a certain degree of responsibility since it deals with issues of utmost importance that affect society as a whole. As a consequence, drafters exercise greatest care in the choice of words and syntax so as to make the text as precise and unambiguous as possible. Readers must interpret from what they read in the text exactly what was intended, and not an unintended message that may be inferred through the ambiguity of the language in which the Act was drafted.

Moreover, legislative texts require a certain degree of formality and thus tend to make use of linguistic elements that satisfy this requirement, such as in the case of the passive voice. Some of the elements that are considered as leading formality to the text are criticised by the Plain English defenders, giving rise to debate whether to follow the Plain English principles or retain formality through the use of the traditional legal drafting techniques. Rendering the text plain does not only entail changing the terms and some linguistic feature into a modern style, but it involves presenting the information of the Act in a simpler way which nevertheless takes into account the principles of precision, unambiguity and all-inclusiveness essential in this kind of text.

It must be mentioned that the conclusions reached in this study are unavoidably limited due to the fact that the analysis has been based on only two Acts of Parliament and the results, therefore, can merely be considered a first approach to the study of the evolution of UK legal drafting towards a more modern style. In this sense, further studies could work with a larger number of Acts so as to have a larger corpus. Another option could focus on the analysis of the degree of intelligibility for native speakers in 
order to see whether lay understanding of contemporary legal drafting has increased or not, providing ethnographic data on the subject.

\section{Notes}

1. Available on: http://www.presidency.ucsb.edu/ws/?pid=30539, accessed: 9th June 2015.

\section{References}

Adler, Mark (2012): "The Plain English Movement". In P. M. Tiersma and L. M. Solan, eds., The Oxford Handbook of Language and Law. New York: Oxford University Press, 67-83.

Assy, Rabeea (2011): "Can the Law Speak Directly to its Subjects? The Limitation of Plain Language". Journal of Law and Society 38(3): 376-404.

Barleben, Dale (2003): Plain English Movement and Present-day English Registers. In: http://homes.chass.utoronto.ca/ cpercy/courses/6362/2/Plain.htm [Accessed: 10th June 2015].

Bhatia, Vijay (1994): "Cognitive structuring in legislative provisions". In J. Gibbons, ed., Language and the Law. New York: Longman Publishing, 136-155.

Butt, Peter and Castle, Richard (2006): Modern Legal Drafting. A Guide to Using Clearer Language. New York: Cambridge University Press.

Garner, Bryan A. (1995): A Dictionary of Modern Legal Usage. New York: Oxford University Press.

Haigh, Rupert (2015): Legal English. Abingdon: Routledge, Taylor \& Francis Group.

Hunt, Brian (2002a): "Plain Language in Legislative Drafting: Is it Really the Answer?" Statute Law Review 23(1): 24-46.

Hunt, Brian (2002b): "Plain Language in Legislative Drafting: An Achievable Objective or a Laudable Ideal?" Statute Law Review 24(2): 112-124.

Kimble, John (1992): "Plain English: A Charter for Clear Writing (Part 3)". Michigan Bar Journal 71: 1307-1302.

Kimble, John (1994-1995): "Answering the Critics of Plain Language". The Scribes Journal of Legal Writing 5: 51-85.

Kimble, John (1996-1997): "Writing for Dollars, Writing to Please". The Scribes Journal of Legal Writing 6: 1-38.

Merriam-Webster Dictionary. http://www.merriam-webster.com.

Plain English Campaign (1996): Language on Trial. The Plain English Guide to Legal Writing. London: Robson Books Ltd.

Tiersma, Peter M. (1999): Legal Language. Chicago: The University of Chicago Press.

UK Acts of Parliament. Available in: http://www.legislation.gov.uk/ [Accessed: 23th June 2015].

Williams, Christopher (2007): Tradition and Change in Legal English: Verbal Constructions in Prescriptive Texts. Bern: Peter Lang. 